 \\ International Journal of Otorhinolaryngology
}

\section{Tumours of Salivary Glands in Sudan}

\begin{abstract}
Keywords: Sa liva ry glands Benign; Malignant tumors
Abstract

Abstract Benign and malignant tumors are rare conditions; it was not uncommonly occurs in salivary glands and usually presented as a painless mass. The presence of pain and facial nerve palsy may indic ate malignant transformation. Diagnosis is made by imaging and biopsies.

Objectives: This study aims to know the pattem of Benign and malignant tumors in salivary glands among Sudanese patients in Khartoum state according to many categories age, gender, clinica presentation and diagnosis.
\end{abstract}

Methods: This is retrospective, cross- sectional, analytic and hospital based study from January 2014 to May 2016. Conducted in Otorhinolaryngological, Head and neck and Oral Maxillofacial hospitals in Khartoum state in Sudan.

Results: The highest percentage of neoplasm is benign more commonly as pleomorphic adenoma in minor glands. Malignant tumor is commonly affected the parotid glands of predominance in adenoid cystic carcinoma followed by mucoepidemoid carcinoma.

Conclusion: Benign and malignant tumors which occur in sa livary glands were commonly pleomomhic adenoma and adenoid cystic carcinoma respectively.

\section{Introduction}

The salivary gland neoplasm presented with a slowly growing painless masses. Parotid neoplasms most commonly occur in the tail of the gland. Submandibular neoplasms often appear with diffuse enlargement of the gland and sublingual tumors produce a palpable fullness in the floor of the mouth $[1,2]$.

A total of 285 patients were enrolled. Among them, 230 (80.7\%) had parotid gland and 55 (19.3\%) had submandibular gland masses. Following a definitive histopathological examination, the most common benign tumor was pleomorphic adenoma (52.6\%), whereas malignant tumors were mucoepidermoid carcinoma (2\%) and squamous cell carcinoma (2\%) [3].

Facial paralysis or other neurologic deficit associated with a salivary gland mass indicates malignancy and the significance of painful salivary gland masses is not entirely clear. Pain may be a feature associated with both benign and malignant tumors and it may arise from suppuration or hemorrhage into the mass or from infiltration of a malignancy into adjacent tissue. The suspicious also my include size, mobility, and extent of the mass, as well as its fixation to surrounding structures and tenderness. Facial nerve should be assessed carefully to identify any weakness or paralysis because usually it indicates a malignant lesion with infiltration into the nerve [2]. Minor salivary gland tumors have varied presentations depending on the site of origin. Painless masses on the palate or floor of the mouth are the most common presentation of minor salivary neoplasm [4]. Distinguishing malignant neoplasm from benign one at initial presentation may not be possible until a biopsy is performed.

\author{
Sharfi Ahmed ${ }^{1 *}$, Yousif $O Y^{2}$ and Abuzeid $\mathrm{M}^{3}$ \\ ${ }^{1}$ ORL head and neck surgery, University of Omdurman Islamic, \\ Sudan \\ ${ }^{2}$ University of Khartoum, Sudan \\ ${ }^{3}$ University of Bahr El Ghazal, Sudan
}

\section{*Address for Correspondence}

Sharfi Ahmed, Faculty of Medicine, ORL head and neck surgery, University of Omdurman Islamic, P.O.Box: 8019 khartoum, Sudan, E-mail: doctorsharfi@gmail.com

Submission: 2 February, 2018

Accepted: 5 March, 2018

Published: 12 March, 2018

Copyright: () 2018 Ahmed S, et al. This is an open access article distributed under the Creative Commons Attribution License, which permits unrestricted use, distribution, and reproduction in any medium, provided the original work is properly cited.

Both types typically present as a painless mass in the gland. Findings that are concerning for malignancy include pain, facial paresis, fixation of the mass to the skin or underlying tissue, and palpable neck lymphadenopathy [4-7] .

In another study $67.5 \%$ were benign and $32.55 \%$ were malignant. The majority of cases occurred in the parotid $67.7 \%$ followed by minor glands $22.8 \%$ and submandibular gland $9.5 \%$. The tumors affected in the study of four hundred and nine biopsies were performed in 381 patients (ages, 2-97 years; mean, 55.9). There were two minor complications. Biopsy was diagnostic in $98.3 \%$. There were eight false negatives. The diagnostic values for malignancy were: sensitivity $89.6 \%$, specificity $100 \%$, Positive Predictive Value (PPV) $100 \%$ and Negative Predictive Value (NPV) $98 \%$. For the detection of neoplasms were: sensitivity $98.7 \%$, specificity $99 \%$, PPV $99.7 \%$ and VPN 96.1\% [8].

Pleomorphic adenoma was the most common represented 54.2\% of all cases, followed by mucoepidermoid ca $13.5 \%$, warthin tumor 8.5\% and Adenoid cystic carcinoma 7.9\% [9].

Shafcat from Kashmir had undertaken a period of two years with particular reference to age, sex, site and histological types as per WHO classification. Out of 100 cases diagnosed on FNAC histopathological examination was done only in 66 cases. Diagnosis correlated with FNAC diagnosis in 65 cases with accuracy of $98.4 \%$. The principal site was the parotid (70\%).

Accuracy of ultrasound-guided core-needle biopsy in salivary gland tumours is very high, with a very high sensitivity and an absolutely reliable diagnosis of malignancy. It should be considered the technique of choice when a salivary gland tumours is detected [8].

Pleomorphic adenoma (73\%) formed the largest group of tumors in most sites and benign tumors were common in $3^{\text {rd }} \& 4^{\text {th }}$ decades while as malignant tumors were more common in $4^{\text {th }} \& 5^{\text {th }}$ decades. Painless swelling was the commonest presentation and present in $99 \%$ cases $[7,10]$. Ultrasound-guided core-biopsy is the technique of choice in salivary glands nodules $\bullet$ Sensitivity, specificity for detecting neoplasms (which should be resected) are around 99\% • Diagnosis 
of malignancy in core-biopsy is absolutely reliable $•$ A ultrasoundguided core-needle biopsy result of "normal tissue", however, warrants repeating the biopsy • Complication rate is very low [8].

Sulieman and Shummo founded that a $70 \%$ of the salivary gland tumors were parotid tumors, $20 \%$ were submandibular tumors and $10 \%$ were sublingual tumors and high incidence of malignancy was seen in salivary gland of $47 \%$ of cases. The predomince is for male and $5^{\text {th }}$ decade of life showed the high incidence of involvement. The use of tombac (local snuff) appears to have strong relation with the increases of malignant tumors [11].

Fine-needle aspiration biopsy is a safe and simple diagnostic tool for the diagnosis of salivary gland masses and has a relatively high sensitivity and specificity. It may provide valuable information for patient counseling and surgical planning. The major drawbacks include a lower sensitivity than specificity and a relatively high rate of non-diagnostic results [3].

In benign salivary glands tumor women was affected in $61 \%$ and male: female ratio was $1: 1.6$. The parotid gland tumors were frequently in $68.5 \%$ with age ranged from 1 to 88 years (median $45 \mathrm{yrs}$ ) [7,12]. The most common malignancy is mucoepidermoid carcinoma (10.1\%) in second and sixed decade of equal gender distribution M:F ratio and predominately in palate. Squamous cell carcinoma (10.9\%) and adenoid cystic carcinoma (21.9\%) were most common malignancy in the major and minor gland respectively $[6,13]$. A positive smoking history in $88 \%$ of men. The age distribution increase over each decade 1 (4.8\%), 2 (5.5\%) and 8 (16\%) in parotid gland [14]. Adenoid cystic carcinoma is rare tumor accounting for only $1 \%$ of all malignant tumor of oral and maxillofacial region. It account for $22 \%$ of all salivary gland malignancies and is one of the most common malignant tumor of the minor salivary glands. It is the most common in fifth and sixth decades of life with male predominance. It is slow growing tumor and usually asymptomatic till it has invaded local nerves and structures with cervical lymph node metastasis [15]. P16 is encoded by the CDKN2A gene, which is recognized as a tumor suppressor due to its inactivation in many types of tumors. However, p16 overexpression is also linked to adverse tumor parameters and it's overexpression was cell-type dependent in Adenoid cystic carcinomas in the lacrimal gland, while HPV infection was negative. P16 overexpression was unrelated to HPV infection but the mechanism of p16 overexpression needs to be further investigated in ACCs in the lacrimal gland [16].

\section{Patients and Methods}

This retrospective hospital based cross-sectional study from January 2014-May 2016. Study was done in Khartoum ENT hospital, Ibnsina specialized hospital, Khartoum dental teaching hospital and Africa specialized hospital. For 73 patients presented to these hospitals complaining of salivary glands swelling. In this study the authors included all patients presented with salivary gland tumours. And they excluded all patients with secondary metastasis to salivary glands and severely ill patients.

Data collection: Detailed will structured questionnaire was filled for each hospital respondent after obtaining the consent.

Data management and analysis: Data analyzed using statistical Package for Social Sciencel.
Patient with Pleomorphic Adenoma of the Parotid Gland

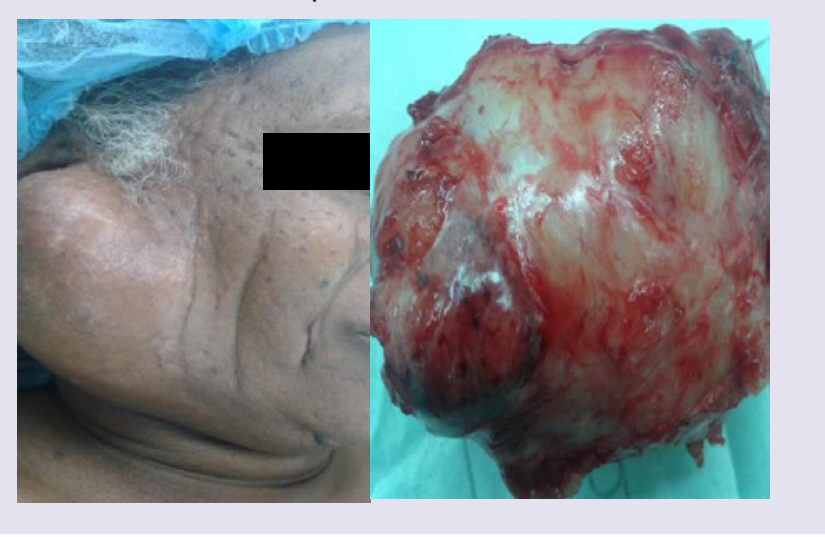

Ethical clearance: I explained verbally to any patient the aim of the study, data collection, the need of investigations and regular follow up. Privacy of patient is the most of our priority.

\section{Results}

The number of patients included in this study was 73. Collected from 2 departments Otorhinolaryngology and Oro-maxillofacial departments in Khartoum hospitals.

Thirty patients $(41.1 \%)$ males compared to 43 patients $(58.9 \%)$ females with a predominance of female and M: F ratio was 1:1.8 (Figure 1).

Regarding the affected age group in this study $0-15$ years 3 patients

\begin{tabular}{|c|c|c|}
\hline \multicolumn{3}{|c|}{$\square$ female $\square$ male } \\
\hline \multicolumn{3}{|c|}{ Figure 1: Gender distributions. } \\
\hline Age groups & Frequency & Percentage \\
\hline Less than 15 & 3 & 4 \\
\hline $16-25$ & 10 & 13.7 \\
\hline 26-35 & 16 & 22 \\
\hline $36-45$ & 17 & 23.4 \\
\hline $46-55$ & 9 & 12.3 \\
\hline $56-65$ & 11 & 15 \\
\hline $66-75$ & 7 & 9.6 \\
\hline Total & 73 & 100 \\
\hline
\end{tabular}


Table 2: Symptoms of patients.

\begin{tabular}{|c|c|c|}
\hline Symptoms of salivary gland diseases & Number of patients & Percentage \\
\hline Pain with food chewing & 24 & $33 \%$ \\
\hline Swelling & 73 & $100 \%$ \\
\hline Xerostomia & 3 & $4 \%$ \\
\hline Dry eye & 3 & $4 \%$ \\
\hline Obstructive symptoms & 3 & $4 \%$ \\
\hline Dental symptoms & 2 & $2.70 \%$ \\
\hline Inability to mouth opening & 3 & $4 \%$ \\
\hline Facial weakness & 3 & $4 \%$ \\
\hline
\end{tabular}

Table 3: Signs of the study group.

\begin{tabular}{|l|l|l|}
\hline Sign of salivary gland diseases & Number of patient & Percentage \\
\hline Mass & 73 & $100 \%$ \\
\hline Regular shape of the glands & 55 & $75.30 \%$ \\
\hline Cervical lymph node & 7 & $9.60 \%$ \\
\hline The presence of ulcer & 4 & $5.40 \%$ \\
\hline Pus from the duct & 4 & $5.40 \%$ \\
\hline Facial paralysis & 7 & $9.60 \%$ \\
\hline Trismus & 4 & $5.40 \%$ \\
\hline
\end{tabular}

Table 4: Uses of radiological image as a diagnostic tool for patients.

\begin{tabular}{|l|l|l|}
\hline Radiology images & Number of patients & Percentages \\
\hline Plan x-ray & 51 & $69.80 \%$ \\
\hline CT scan & 73 & $100 \%$ \\
\hline Ultrasound & 3 & $4.00 \%$ \\
\hline
\end{tabular}

Table 5: Result of fine needle aspiration cytology.

\begin{tabular}{|c|c|c|}
\hline FNAC result & Frequency & Percentage \\
\hline Polymorphic adenoma & 51 & 69.8 \\
\hline Adenoid cystic carcinoma & 4 & 5.4 \\
\hline Acinic cell carcinoma & 1 & 1.4 \\
\hline Myoepithilial carcinoma & 1 & 1.4 \\
\hline Mucoepidermoid carcinoma & 3 & 4 \\
\hline Haemangioma & 1 & 1.4 \\
\hline Not done & 12 & 16.6 \\
\hline Total & 73 & $100 \%$ \\
\hline
\end{tabular}

(4\%), followed by 16-25/26-35 years 10 and 16 patients respectively. Between 36-45 years 17 patients (23.4\%), followed by $46-55$ years 9 patients (12.3\%) then $56-65$ years 11 patients $(15.0 \%)$, finally between 66-75 7 patients (9.6\%) (Table1).

Regarding residence the largest percentage of patients of Khartoum state; in Omdurman were 19pts (26.0\%), then Khartoum were 16 pts $(21.8 \%)$, Bahri were 14pts (19.2\%). The patients out of Khartoum state were 24pts (33.0\%) (Figure 2).

Regarding the socioeconomic status; a low socioeconomic status was the commonest group affected in this study $54.5 \%$, moderate socioeconomic status in $44.4 \%$ and lastly high socioeconomic status

\section{in $1.1 \%$ (Figure 3 ).}

Risk factors may predispose in salivary gland disorders were: smoking in 5.1\%, alcohol in $0.6 \%$ and snuffing in $0.6 \%$ (Figure 4 ).

Regarding the symptoms of salivary gland diseases were organized as follows: gland swelling in 73 patients $(100 \%)$, pain with food chewing presented in 24 patients (33\%), xerostomia was founded in 3 patients (4.0\%), dry eye in 3patients (4\%), obstructive symptoms: founded in 3patients (4\%), 3 patients with inability to swallow, dental symptoms in 2 patients $(2.7 \%)$ and finally facial weakness founded in 3 patients (4\%) (Table 2$)$.

Regarding the signs of salivary gland diseases, mass was found in 73 patients (100\%), the regular shape swellings founded in 55 patients (75.3\%), cervical lymph node enlargement in this study founded in 7 patients $(9.6 \%)$ and ulcerations in 4 patients (5.4\%). Pus was discharged from duct in 4 patients $(5.4 \%)$, followed by trismus in 4 patients $(5.4 \%)$. Facial nerve was founded paralyzed in 7 patients

Table 6: The histological results of the patients.

\begin{tabular}{|c|c|c|}
\hline Histopatological results & frequency & Percentage \\
\hline Pleomorphic adenoma & 54 & 74 \\
\hline Adenoid cystic carcinoma & 6 & 8 \\
\hline Mucoepidermoid carcinoma & 5 & 7 \\
\hline Acinic cell carcinoma & 3 & 4 \\
\hline Warthintumour & 2 & 2.8 \\
\hline Squamus cell carcinoma & 1 & 1.4 \\
\hline Haemangioma & 1 & 1.4 \\
\hline Myoepithelial carcinoma & 1 & 1.4 \\
\hline Total & 73 & $100 \%$ \\
\hline
\end{tabular}

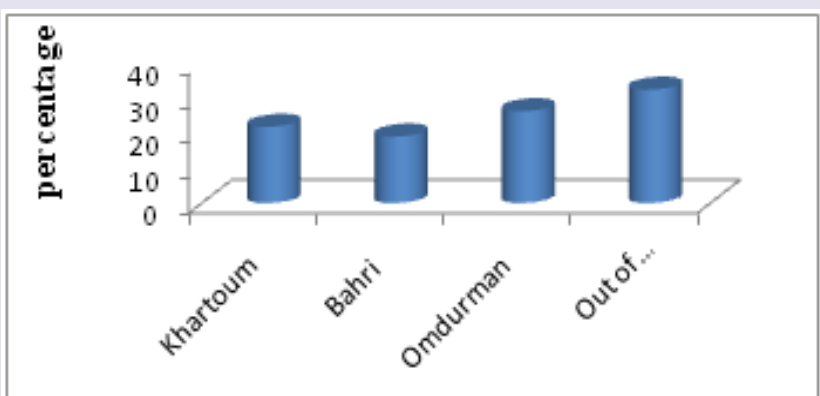

Figure 2: Patients residence.

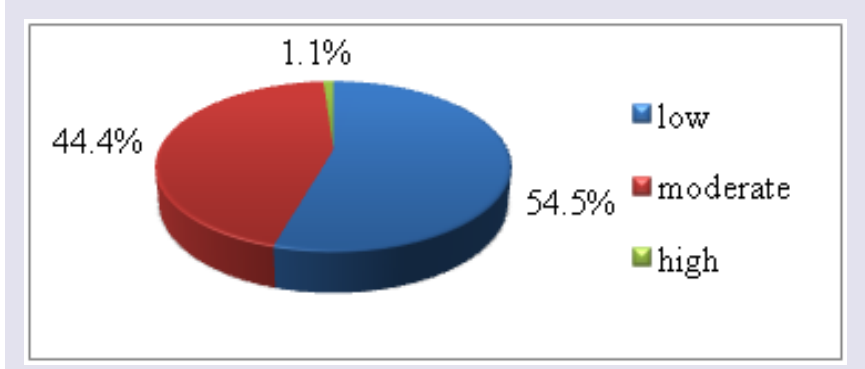

Figure 3: Socioeconomic status of the patients. 


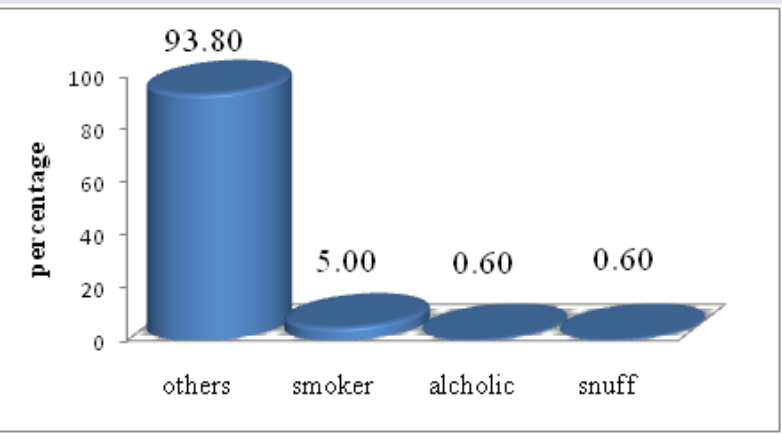

Figure 4: Risk factors that contributes in salivary gland diseases.

\section{(9.6\%) (Table 3).}

Regarding the radiological results: plain $\mathrm{x}$-rays was done in 51 patients $(69.8 \%)$ CT scan in 73 patients $(100 \%)$ and ultrasound in 3 patients (4\%) (Table 4).

The results finding of FNAC were: pleomorphic in 51 patients (69.8\%), adenoid cystic carcinoma in 4 patients (5.4\%), acinic cell carcinoma in 1 patient (1.4\%) and mucoepidermoid carcinomain 3 patient (4\%) (Table 5).

According to the results of histopathology : pleomorphic adenoma in54 patients(74\%), chronic ,adenoid cystic carcinoma in 6 patients (8\%) mucoepedermoid carcinoma in 5 patients $(2.8 \%)$ and acinic cell carcinoma in 3 patients [17].

\section{Discussion}

Salivary gland neoplasm presented with a slowly growing painless masses in which Parotid neoplasms are the most commonly occur $[1,2]$.

The total number of patients in this study were 73 patients with mean age was $30 \pm \mathrm{SD}$ and this was compatible to Torabinia and, Ahrnad $[7,10]$.

Female more affected than male with ratio 1:8. and this is also in agreement with Zaho, Pillmer and Torabinia $[7,17,18]$. In contrast to Sullieman, Yoo GH and Jasomention who mentioned the male predominance $[11,14,1,5]$.

The commonest major gland affected was parotid gland this compatible with result of Harrison and to Yoskovitch [19,20].

Risk factor that contributed to salivary gland diseases in this study showed smoking $5.1 \%$ snuffing $0.6 \%$ alcohol $0.6 \%$ which is the same result to Sullieman and Yoo GH $[11,14]$.

The common symptom is pain with food chewing which is similar to Yoskovitch and Siddiqui $[19,21]$.

Regarding signs of salivary diseases in this study: the moderate size swelling is most common presentations $89.9 \%$ which is similar to Yoskovitch, Harrison and Lee $[2,19,20]$.

The commonest radiological study used in this study was CT scan in all patients $100 \%$ and this in agreement with Yoskovitch [19].

Regarding the result of FNAC in diagnosis of salivary gland disease showed $69.8 \%$ pleomorphic adenoma is the commonest which is the same as Ahmad and Torabinia who reported that pleomorphic adenoma is the commonest tumor $[4,10]$.

Regarding the histopatholgical results: The most common tumour is pleomorphic adenoma in $74 \%$ this is similar to Jaberwho reported that the commonest type of tumors was pleomorphic adenoma [12,22].

\section{Conclusion}

The most common neoplasm of salivary gland is the benign tumors, mainly the pleomorphic adenoma and the majority of them in the parotid gland in young adults. Mucoepidermoid carcinoma is the most common malignant tumor predominantly seen in female and in minor salivary glands. Facial nerve palsy seen mainly in malignant tumors and FNAC is a useful method in diagnosis. CT scan has a grateful role in diagnosing the neoplastic lesion.

\section{References}

1. Madani G, Beale T (2006) Inflammatory conditions of the salivary glands. Semin Ultrasound CT MR 27: 440-451.

2. Lee SC, Johnson JT (2009) Salivary glands Neoplasms. eMedicine Specialties.

3. Edizer DT, Server EA, Yiğit Ö, Yıldız M (2016) Role of fine-needle aspiration biopsy in the management of salivary gland masses. Turk Arch Otorhinolaryngol 54: 105-111.

4. To VS, Chan JY, Tsang RK, Wei WI (2012) Review of salivary gland neoplasms. ISRN otolaryngology 2012: 6.

5. Akar HH, Patıroglu T, Duman L (2014) A selective IgA deficiency in a boy who presented recurrent parotitis. Eur J Microbiol Immunol (Bp) 4: 144-146.

6. Main JH, Orr JA, McGurk FM, McComb RJ, Mock D (1976) Salivary gland tumors: review of 643 cases. J Oral Pathol Med 5: 88-102.

7. Torabinia N, Khalesi S (2014) Clinicopathological study of 229 cases of salivary gland tumors in Isfahan population. Dent Res J (Isfahan) 11: 559563.

8. Del Cura JL, Coronado G, Zabala R, Korta I, Lópezl (2018) Accuracy and effectiveness of ultrasound-guided core-needle biopsy in the diagnosis of focal lesions in the salivary glands. Eur Radiol 31.

9. Ito FA, Ito K, Vargas PA, de Ameida OP, Lopes MA (2005) Salivary gland tumors in a Brazilian populations: a retrospective study of 496 cases. Int $J$ Oral Maxillofac Surg 34: 533-536.

10. Ahrnad S, Lateef M, Ahmad R (2002) Clinicopathological study of primary salivary-gland tumors in Kashmir. JK-practitioner 9: 231-233.

11. Suliman AM, Ibrahim LM, Sbummo A (2003) The incidence of salivary glands tumours among the sudanese 2: 29-32.

12. Jaber MA (2006) Intraoral minor salivary gland tumors: a review of 75 cases in a Libyan population. J Oral Maxillofac Surg Med Pathol 35: 150-154.

13. Otoh EC, Johnson NW, Olasoji H, Danfillo IS, Adeleke OA (2005) Salivary gland neoplasms in Maiduguri, northeastern Nigeria. Oral diseases 11: 386391.

14. Yoo GH, Eisele DW, Driben JS, Johns ME, Askin FB (1994) Warthin's tumor: A 40year experience at the johns hopkins hospital. The Laryngoscope 104: 799-803.

15. Jaso J, Malhotra R (2011) Adenoid cystic carcinoma. Archives of pathology \& laboratory medicine 135: 511-515.

16. Wang Y, Tian Y, Lin J, Chen L, Wang L, et al. (2018) Assessment of p16 expression and HPV infection in adenoid cystic carcinoma of the lacrimal gland. Mol Vis24: 143-152. 
Citation: Ahmed S, Yousif OY, Abuzeid M. Tumours of Salivary Glands in Sudan. Inter J Otorhinolaryngology. 2018;5(1): 5.

\section{ISSN: 2380-0569}

17. Pillmer SR, Matterson EL, Jacobsson LT, Martern PB, Melton LJ (2001) Incidence of phiysicion- diagnosed primary sjogren syndrome in residents of Olmsted country, Minnesota. Mayo Clin Proc 76: 593-599.

18. Zhao YF, Jia Y, Chen XM, Zhang WF (2004) Clinical review of 580 ranulas. Oral Surg Oral Med Oral Pathol Oral Radiol Endod 98: 281-287.

19. Yoskovitch A (2015) Submandibular sialadenitis / Sialadenosis. eMedicine.

20. Harrison JD (2010) Modern management and pathophysiology of ranula literature review. Head Neck 32: 1310-1320.

21. Siddiqui SJ (2002) Sialolithiasis; an unusually large submandibular salivary gland stone. Br Dent J 193: 89-91.

22. Kassan SS, Moutsopouios HM (2004) Clinical manifistations and early diagnosis of sjogrensyndrome. Arch of intern Med 164: 1275-1284. 